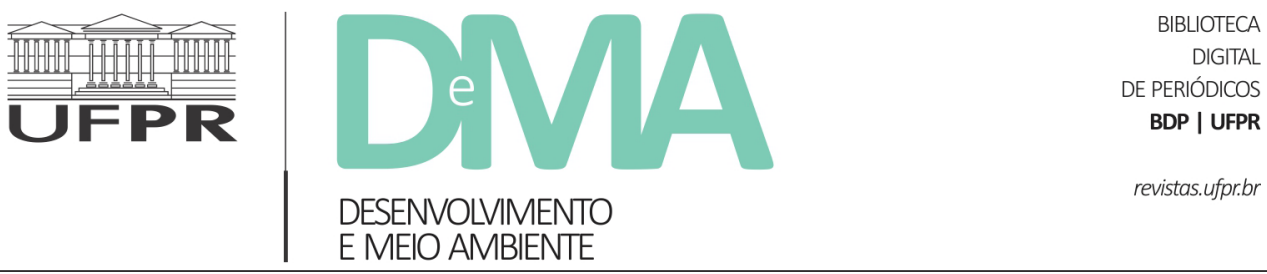

\title{
Contribuições do conhecimento ecológico local para o ordenamento da pesca esportiva e conservação de robalos na Reserva de Desenvolvimento Sustentável Barra do Una, Peruíbe/SP
}

\section{Contributions of local ecological knowledge to the organization of recreational fishing and conservation of snook in the Sustainable Development Reserve Barra do Una, Peruíbe/SP}

\author{
Lizandro Rogério de Paula FERREIRA ${ }^{1}$, Fabiola Andrea Chofard ADAMI ${ }^{1}$, Patrícia de OLIVEIRA ${ }^{1}$, Walter \\ BARRELLA $^{1}$, Matheus Marcos ROTUNDO ${ }^{1}$, Milena RAMIRES ${ }^{1^{*}}$
}

${ }^{1}$ Universidade Santa Cecília (UNISANTA), Santos, SP, Brasil.

*E-mail de contato: milena@unisanta.br

Artigo recebido em 15 de outubro de 2020, versão final aceita em 19 de maio de 2021, publicado em 23 de dezembro de 2021.

RESUMO: O desenvolvimento da pesca esportiva pode proporcionar benefícios sociais e econômicos às populações locais, contudo gera impactos negativos ao meio ambiente se não houver gestão efetiva. A presente pesquisa teve como objetivo analisar as contribuições do conhecimento ecológico local para o ordenamento da pesca esportiva e conservação de robalos na Reserva de Desenvolvimento Sustentável (RDS) Barra do Una, Peruíbe/SP. Foram entrevistados 27 pescadores artesanais, envolvidos com a pesca esportiva, através de questionários semiestruturados contendo questões sobre dados socioeconômicos, atividade pesqueira, conhecimento ecológico local e as relações com a pesca esportiva, especialmente sobre prestação de serviços e aspectos referentes a conservação dos robalos. A pesca esportiva tem se tornado uma alternativa de renda para as famílias de pescadores artesanais da Barra do Una, que aplicam seus conhecimentos sobre os recursos pesqueiros nesta nova prática. A pesca esportiva na RDS Barra do Una tem potencialidades como atividade de lazer e geração de renda através das atividades associadas ao turismo de pesca. Essa característica é bastante representativa tanto para os turistas que visitam a região quanto para os próprios moradores locais. Porém, fica clara a necessidade de ordenamento desta atividade para o alcance do seu potencial de conservação ambiental e desenvolvimento socioeconômico local. Assim, foram propostas medidas de ordenamento com base no conhecimento ecológico local dos pescadores artesanais, na legislação vigente e informações técnicas já existentes para o setor.

Palavras-chave: pesca recreativa; pesca artesanal; Centropomidae; manejo pesqueiro; Mosaico Juréia Itatins. 
ABSTRACT: The development of recreational fishing can provide social and economic benefits to local populations. However, it generates negative impacts on the environment if there is no effective management. This research aimed to analyze the contributions of local ecological knowledge to the planning of recreational fishing and conservation of snooks in the Barra do Una Sustainable Development Reserve, Peruíbe/SP. Twenty-seven artisanal fishers involved in recreational fishing were interviewed through semi-structured questionnaires containing questions about socio-economic data, fishing activity, local ecological knowledge, and relationships with recreational fishing, especially regarding services and aspects related to the conservation of snooks. Recreational fishing has become an income alternative for the artisanal fishing families of Barra do Una, who apply their knowledge of fishing resources in this new practice. Recreational fishing in RDS Barra do Una has potential as a leisure activity and income generation through activities associated with fishing tourism. This feature is quite representative both for tourists visiting the region and for residents themselves. However, it is clear the need to organize this activity to reach its potential for environmental conservation and local socioeconomic development. Thus, management measures were proposed based on local ecological knowledge of artisanal fishermen's current legislation and technical information already available for the sector.

Keywords: recreational fishing; artisanal fishing; Snook; fisheries management; Mosaic Juréia Itatins.

\section{Introdução}

A pesca esportiva é uma das atividades de turismo e lazer mais praticadas mundialmente, envolvendo vários serviços como transporte, alimentação, hospedagem, venda de materiais e receptivos. É uma importante alternativa de renda para famílias de pescadores artesanais, que vivem em pequenas comunidades e direcionam suas atenções e implicam seus conhecimentos sobre os recursos pesqueiros nesta atividade (Catella et al., 2008; Freire, 2010; Barcellini et al., 2013; Tsuruda et al., 2013; Molitzas et al., 2019; Silva et al., 2016). Proporciona benefícios sociais e econômicos, contudo pode acarretar danos e gerar impactos ao meio ambiente se não houver controles e critérios de gestão (Teramoto e Diegues, 2014).

Apesar da ampla disseminação e da existência de códigos de conduta, orientações técnicas e diretrizes éticas, a gestão desta modalidade deve apresentar uma abordagem econômica e sociocultural (FAO, 2012), pois ainda é pouco conhecida e quase não existem dados que ordenem a atividade e orientem políticas públicas (Pereira et al., 2008; Encontro Nacional da Pesca Amadora, 2010). A qualidade e representatividade amostral das informações biológico-pesqueiras existentes, aplicadas à pesca esportiva, como lista de espécies-alvo, avaliação dos estoques pesqueiros, esforço aplicado e descrição das técnicas utilizadas ainda são insuficientes para o planejamento e ordenamento da atividade, bem como para o mapeamento das áreas com maior concentração e potencial para prática sustentável, ecológica e socialmente (Cowx et al., 2010; Freire, 2010).

Informações sobre a magnitude, importância e os efeitos da pesca esportiva em países em desenvolvimento são extremamente necessárias, mesmo porque o ordenamento da pesca esportiva pode representar uma alternativa de renda para diversas comunidades locais, sobretudo aquelas inseridas em áreas continentais remotas e nas comunidades costeiras, ambas, geralmente, localizadas em áreas com baixos índices de desenvolvimento humano. Dessa forma, a pesca esportiva gera uma preocupação mundial de conservação que é o desenvolvimento 
de estratégias que visem a sustentabilidade dessa atividade (Cooke e Cowx, 2004; Arlinghaus et al., 2016; Cooke et al., 2016).

A relação entre pescadores esportivos e populações locais é o fator mediador das práticas de uso dos recursos pesqueiros (Dalton et al., 2015; Evans et al., 2015). O conhecimento dos pescadores locais tem sido instrumental em uma série de projetos de gestão da pesca (Granek et al. 2008; Kroloff et al. 2019), já que estas interações etnoecológicas, pautadas pelas experiências e observações refletem na construção de um detalhado sistema de conhecimento sobre condições ambientais e dinâmicas ecológicas das espécies (Marques, 2001; Davis e Wagner, 2003). Assim, uma boa estratégia de manejo dos ambientes pesqueiros é a incorporação do conhecimento local e participação efetiva dos pescadores no monitoramento dos recursos (Johannes et al., 2000; Berkes, 2007). Tanto o conhecimento biológico, quanto o local sobre peixes, podem ser aprofundados e utilizados no estabelecimento de ações efetivas de manejo (Silvano et al., 2006; Castello, 2007; Bennett, 2016).

No litoral sul do Estado de São Paulo, uma forte interação, entre as modalidades de pesca artesanal e esportiva, é permeada pelo grande interesse nos robalos, principalmente o robalo flecha - Centropomus undecimalis e o robalo peva $-C$. parallelus), que estão entre as espécies mais procuradas pelos pescadores esportivos (Barrella et al., 2016; Motta et al., 2016) e profissionais (Souza \& Barrella, 2004; Molitzas et al., 2019). Na Reserva de Desenvolvimento Sustentável Barra do Una, os robalos são explorados pelas duas modalidades há várias décadas (Silva et al., 2016; Molitzas et al., 2019), o que torna de suma importância, o ordena- mento destas atividades, voltado ao uso sustentável dos recursos.

Assim, o objetivo desta pesquisa foi analisar as contribuições do conhecimento ecológico local para o ordenamento da pesca esportiva e conservação de robalos na Reserva de Desenvolvimento Sustentável da Barra da Una, Peruíbe/SP. Com o intuito de fornecer recomendações para a gestão da pesca esportiva, buscou-se associar as informações sobre a prática pesqueira local com dados técnicos-científicos existentes em literatura especializada e legislação vigente.

\section{Metodologia}

Esta pesquisa foi realizada na Reserva de Desenvolvimento Sustentável da Barra do Una (RDSBU), uma Unidade de Conservação Estadual, com área de aproximadamente de 1.487 ha, localizada nos municípios de Peruíbe e Iguape. A RDSBU pertencente ao Mosaico de Unidades de Conservação Juréia Itatins (MUCJI), que abrange municípios da Região Metropolitana da Baixada Santista, do Litoral Sul e Vale do Ribeira, no Estado de São Paulo (Figura 1).

As Reservas de Desenvolvimento Sustentável objetivam compatibilizar a conservação da natureza com o uso sustentável dos seus recursos naturais. Abrigam populações tradicionais com sistemas sustentáveis de exploração de recursos naturais, desenvolvidos ao longo de gerações e adaptados às condições ecológicas locais, desempenhando papel fundamental na proteção e manutenção da biodiversidade (SNUC, 2000). A população humana, residente na RDS Barra do Una é composta por 43 famílias, de origem caiçara, que tem a pesca arte- 
sanal como principal atividade, mas complementam sua renda com atividades ligadas ao turismo de base comunitária, tais como campings, bares, restaurantes, pousadas etc. e o turismo de pesca. Sua praia tem aproximadamente $2 \mathrm{~km}$ de extensão e na comunidade existe um posto de saúde, uma escola (que atende alunos do ensino fundamental), um Centro Comunitário, uma igreja Assembleia de Deus e uma capela de Santo Antônio. Este núcleo de famílias localiza-se a aproximadamente $28 \mathrm{~km}$ do centro de Peruíbe (Prado et al., 2017, Prado e Ramires, 2020).

Foram realizadas entrevistas estruturadas com questionários formulados previamente, com questões abertas e fechadas, sobre atividade pesqueira, dados socioeconômicos e relações com a pesca esportiva. Através de busca ativa pela comunidade, foram identificados os informantes-chave, residentes na RDS Barra do Una, que desenvolvem atividades associadas a pesca esportiva. Além disso,

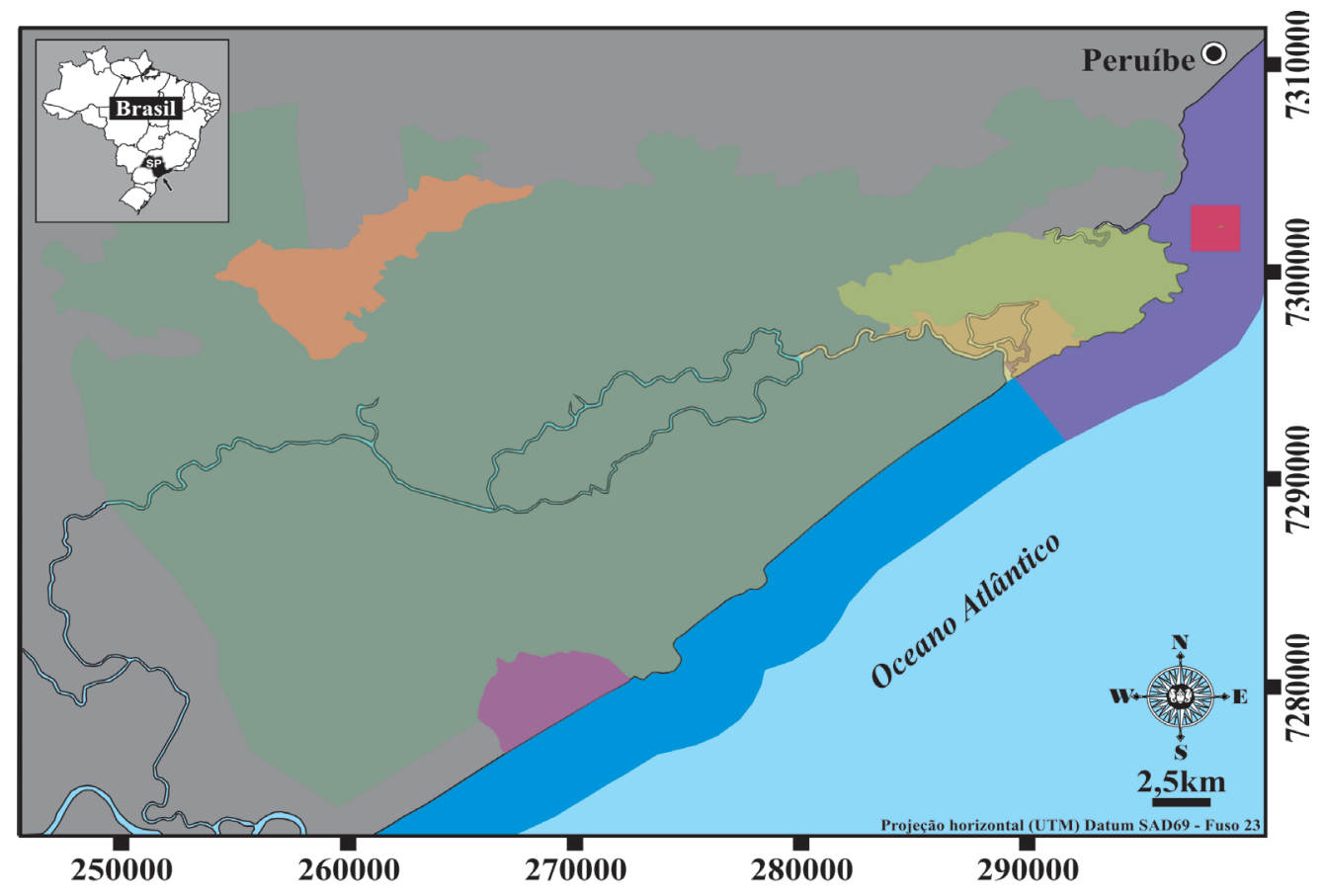

Estação Ecológica Juréia Itatins

APA Marinha Litoral Sul

APA Marinha Litoral Centro

RVS Ilhas do Abrigo e Guararitama

Parque Estadual do Itinguçu

Parque Estadual do Prelado

RDS do Despraiado

RDS da Barra do Una

FIGURA 1 - Mapa dos limites das unidades de conservação do mosaico de unidades de conservação Jureia-Itatins, com destaque para a reserva de desenvolvimento sustentável da Barra do Una, Peruíbe/SP.

FONTE: Adaptado de SMA (2013). 
foi aplicada a técnica do "bola de neve" (Bernard, 2017), que consiste, ao final da entrevista, a tomada de indicações de pessoas também consideradas, na própria comunidade, como especialistas nas atividades relacionadas a pesca esportiva. Como critérios de amostragem associados, também foram estabelecidos: idade igual ou superior a 18 anos, contato direto com atividades da pesca esportiva, residência na comunidade há 10 anos ou mais. As entrevistas etnoecológicas (Marques, 2001) foram aplicadas para o levantamento e análise do conhecimento ecológico local acerca dos aspectos relacionados a taxonomia, alimentação, habitat, reprodução e comportamento dos robalos.

Os principais pontos de pesca, também chamados de pesqueiros, importantes para a pesca esportiva foram caracterizados a partir do conhecimento dos principais guias de pesca esportiva atuantes na RDS Barra do Una. Para a marcação dos pontos foi apresentado ao guia de pesca mais experiente e atuante um mapa com os limites da Unidade de Conservação, para que o ele apontasse os principais pesqueiros e, posteriormente, foi realizada uma expedição para a marcação dos pontos com GPS. Para a caracterização foram registrados aspectos associados às especificidades ambientais dos pontos, tais como: características físicas, salinidade, profundidade, amplitude de marés, sazonalidade e principais iscas utilizadas.

A análise e elaboração das recomendações para o ordenamento da pesca esportiva foram realizadas através da associação do conhecimento ecológico locais com informações obtidas através de pesquisa documental e bibliográfica. Segundo Raupp e Beuren (2004), a diferença básica entre a pesquisa documental e a bibliográfica está no tipo de fonte a ser analisada. A pesquisa bibliográfica busca, essencialmente, a contribuição de diferentes autores através de artigos científicos, livros, instrumentos legais (leis, portarias, decretos etc.) sobre uma determinada temática. A pesquisa documental está baseada em materiais que ainda não foram analisados ou publicados em meios acadêmicos, ou que podem ser analisados e reelaborados, conforme os objetivos de um estudo específico, como, por exemplo, dados brutos de levantamentos públicos, Planos de manejo e de uso de recursos naturais, informações disponíveis em plataformas públicas, relatórios técnicos e diagnósticos, divulgações na mídia, dentre outros.

Os resultados das entrevistas etnoecológicas foram analisados através de análise descritiva, observando as categorias êmicas mais citadas buscando representar o consenso entre os informantes. O conhecimento ecológico local e o científico foram comparados através de tabelas de cognição comparada (Marques, 2001).

A execução do projeto foi aprovada pela Comissão Técnico-Científica da Fundação Florestal (Carta COTEC nº46 /2017 D115/2017) responsável pela gestão das Unidades de Conservação de São Paulo. E os procedimentos metodológicos pelo Comitê de Ética em Pesquisa envolvendo seres humanos da Universidade Santa Cecília (parecer $n^{\circ}$ 1.567.578).

\section{Resultados e discussão}

\subsection{Os pescadores artesanais da RDS Barra do Una e a pesca esportiva}

Foram entrevistados 27 pescadores artesanais da RDSBU, atuantes em atividades relacionadas a 
pesca esportiva. A maioria deles possui o ensino fundamental incompleto (74\%), idade média de 48,3 anos e residem, em média, há mais de 40 anos na comunidade (Tabela 1 ).

A pesca artesanal é a principal atividade econômica das famílias da RDS Barra do Una (81,5\% dos entrevistados), sua prática é "diária” em 70,4\% dos casos e $85,2 \%$ possuem a documentação de pescador profissional. Dentre as atividades secundárias a de piloteiro é a principal, citada por $85,2 \%$ dos entrevistados, comércio de iscas vivas $(11,1 \%)$, guia de pesca $(7,4 \%)$ e aluguel de barco e motor $(3,7 \%)$ também foram citadas pelos pescadores.

Eles trabalham, em média, há 16 anos com a pesca esportiva e a sua frequência está associada aos períodos preferidos pelos pescadores esportivos que, de maneira geral, visitam a comunidade nos fins de semana e feriados. O comércio de iscas vivas é realizado de maneira informal, próximo ou nas próprias residências, demonstrando potencial de crescimento, pois as principais modalidades de pesca esportiva utilizam este tipo de isca.

As atividades relacionadas a pesca esportiva na RDSBU iniciaram, principalmente, a partir de uma demanda local, ocasionada pelo aumento da visitação de pescadores esportivos na comunidade (48,1\%) há décadas e a dificuldade de escoamento e venda a produção pesqueira artesanal. Para 25,9\% dos pescadores o início na atividade aconteceu após aprendizagem com pai ou familiares que já praticavam a pesca esportiva como atividade secundária.

\subsection{O conhecimento ecológico local aplicado aos serviços destinados a pesca esportiva}

As atividades de pesca artesanal e esportiva diferem em relação aos métodos utilizados, a produtividade e objetivo da captura. Enquanto na artesanal são utilizadas rede de emalhe, prioritariamente, a esportiva é praticada com linha, anzol, iscas, molinete/carretilha. Isso reflete na quantidade e riqueza de peixes explorada, fazendo com que o produto da pesca artesanal seja mais diversificado do que da pesca esportiva.

Os pescadores esportivos têm espécies alvo bem definidas, de acordo com os petrechos que utilizam, as características das espécies, as especificidades de habitats e parâmetros ambientais dos pontos de pesca utilizados (pesqueiros), no entanto, Centropomus spp. - robalos são alvo das duas modalidades de pesca.

A maioria dos pescadores artesanais $(77,8 \%)$ identificam duas principais espécies de robalos com binomiais específicos, robalo flecha e robalo peva, atribuídos respectivamente a Centropomus undecimalis e C. parallelus. As principais diferenças apontadas pelos pescadores estão associadas ao tamanho, coloração e formato do corpo. O robalo flecha, é maior (podendo chegar até $30 \mathrm{~kg}$ ), mais comprido e bicudo, com o corpo mais prateado e uma listra negra bem visível. O robalo peva tem coloração mais escura, corpo mais largo e menor (até $4 \mathrm{~kg}$ ). A literatura científica aponta estas diferenças utilizadas para a taxonomia das duas espécies, sendo C. undecimalis (robalo flecha) de corpo estreito e alongado, uma linha lateral ao longo do corpo de coloração escura, lábio inferior protuberante e nadadeira pélvica e caudal amarelada (Figueiredo; Menezes, 1980). Quando adultos ultrapassam os 70 $\mathrm{cm}$ (Nora, 2013). C. parallelus (robalo peva) possui corpo alto, levemente arredondado, linha lateral longitudinal ao corpo com pigmentação amarelada e nadadeira pélvica atinge ou ultrapassa a região anal (Figueiredo e Menezes, 1980). 
TABELA 1 - Perfil socioeconômico dos pescadores locais atuantes em atividades associadas a pesca esportiva na Reserva de Desenvolvimento Sustentável da Barra do Una (SP).

$\mathrm{N}=$ frequência absoluta de citações, $\%=$ frequência relativa de citações. $\mathrm{N}$ total $=27$ entrevistados.

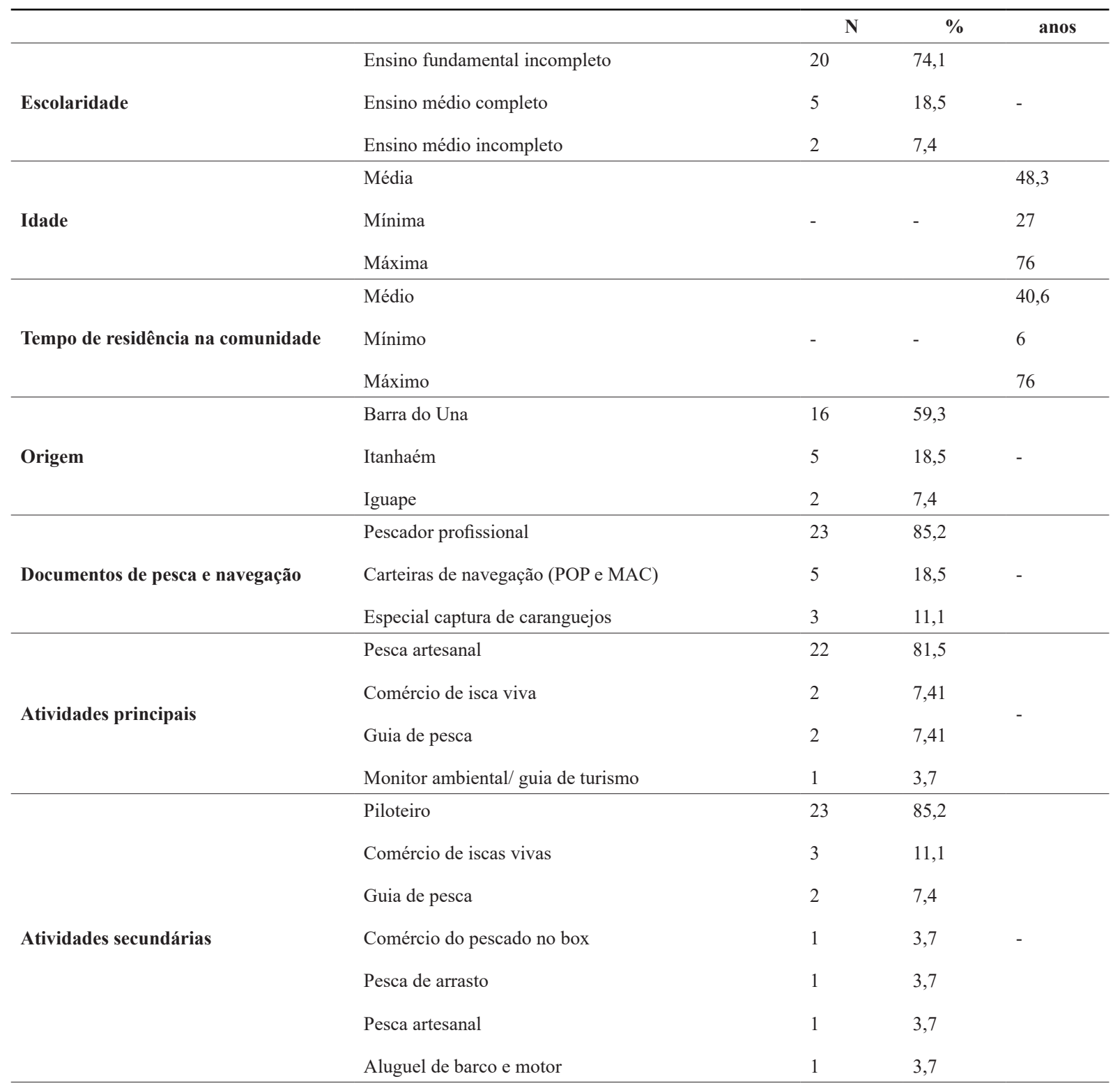




\begin{tabular}{|c|c|c|c|c|}
\hline \multirow{3}{*}{ Tempo de pesca profissional } & Médio & \multirow{3}{*}{-} & \multirow{3}{*}{-} & 30,7 \\
\hline & Mínimo & & & 5 \\
\hline & Máximo & & & 68 \\
\hline \multirow{3}{*}{ Frequência de pesca profissional } & Diária & 19 & 70,4 & \multirow{3}{*}{-} \\
\hline & Semanal & 2 & 7,4 & \\
\hline & Quinzenal & 2 & 7,4 & \\
\hline \multirow{3}{*}{ Tempo de pesca esportiva (anos) } & Médio & \multirow{3}{*}{ - } & \multirow{3}{*}{-} & 16,2 \\
\hline & Mínimo & & & 2 \\
\hline & Máximo & & & 40 \\
\hline \multirow{2}{*}{ Frequência pesca esportiva } & Quando procuram & 19 & 70,4 & \multirow{2}{*}{-} \\
\hline & Fins de semana e feriados & 6 & 22,2 & \\
\hline
\end{tabular}

FONTE: Pesquisa de campo, 2018.

A sazonalidade de captura, segundo os pescadores artesanais, também é diferenciada entre as duas espécies, robalos flecha e peva, sendo o primeiro frequentemente capturado entre os meses de novembro e fevereiro, enquanto o robalo peva é capturado o ano todo (Figura 2).

Assim como indicado pelos pescadores, a maior produtividade pesqueira de Centropomidae também ocorreu durante o verão no complexo estuarino de Cananéia-Iguape (Mendonça \& Katsuragawa, 2001), localizado próximo a área do presente estudo. Segundo Pinto et al. (2018), os parâmetros abióticos, como temperatura e salinidade, influenciam na abundância de C. undecimalis. Assim, considerando que o período de chuvas na região sudeste brasileira ocorre no verão, o maior aporte de águas de origem continental parece influenciar positivamente a abundância do robalo flecha na região, como observado por Barletta et al. (2005), que atribuíram a maior abundância da espécie às variações de salinidade e a maior disponibilidade de habitats durante o período chuvoso no estuário do Rio Caeté, na região norte do Brasil.

O conhecimento dos pescadores artesanais sobre os habitats (Tabela 2) é de extrema importância para os guias de pesca esportiva, pois os pescadores esportivos contam com este conhecimento como critério para a contratação deste serviço. Foram identificados 20 pesqueiros para a prática da pesca esportiva na RDSBU (Figura 3), sendo a maioria utilizados principalmente para a captura de robalos.

Segundo Daros et al. (2016), os juvenis de $C$. parallelus apresentam alta plasticidade quanto a salinidade no complexo estuarino de Paranaguá e, portanto, poderiam ocupar e migrar entre diferentes habitats com variações na residência e movimento migratórios, inclusive, tornando-os vulneráveis à pesca. Motta et al. (2016) também alertaram para esta vulnerabilidade e a alta pressão exercida pela pesca estuarina, principalmente por pescadores esportivos. 

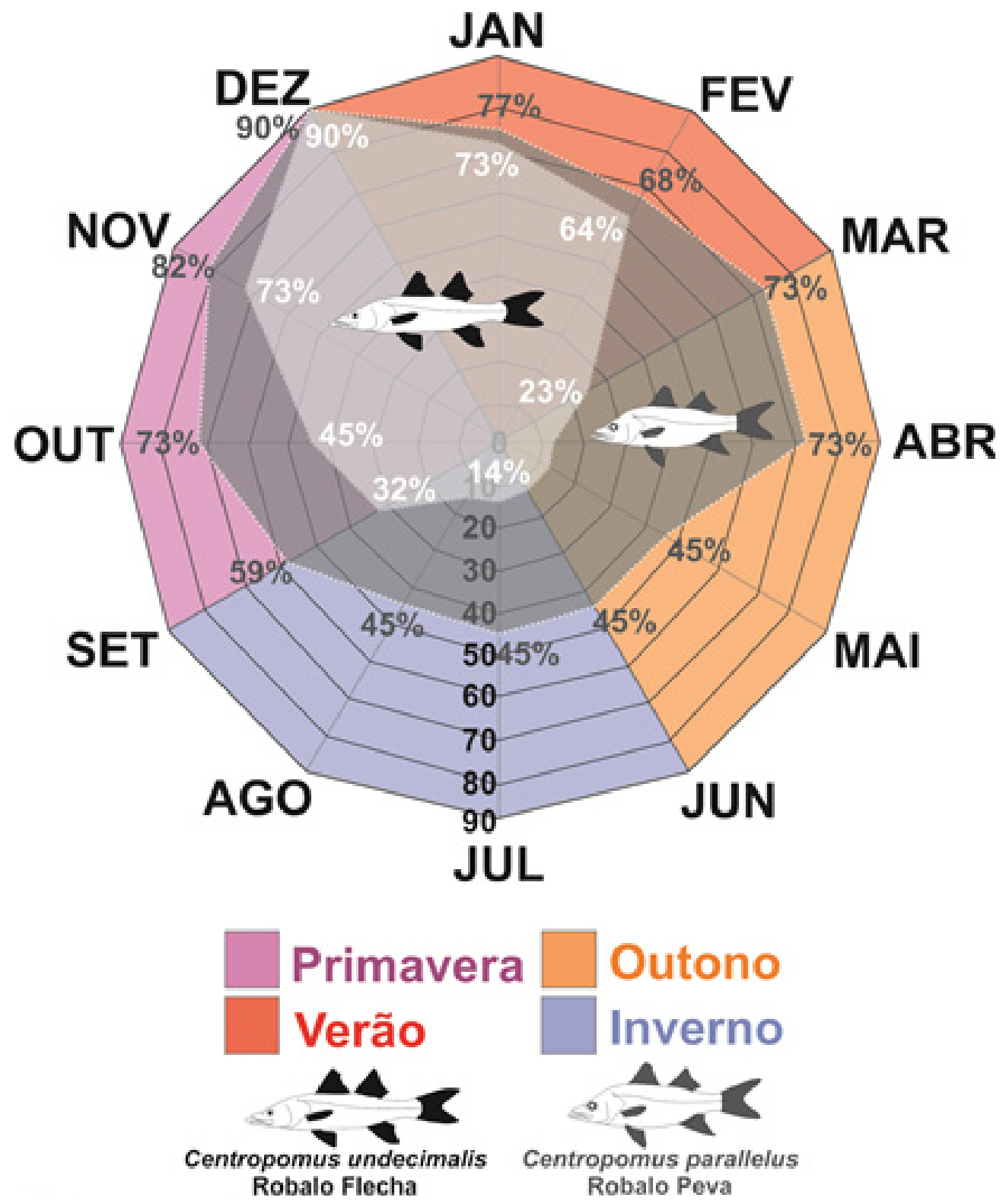

FIGURA 2 - Sazonalidade de captura dos robalos, segundo os pescadores da reserva de desenvolvimento sustentável da Barra do Una, Peruíbe (SP). NOTA: Os valores correspondem a porcentagem de citação das informações nas entrevistas. FONTE: autores. 
TABELA 2 - Conhecimento local dos pescadores artesanais da Barra do Una sobre os habitats dos robalos.

$\mathrm{N}=$ frequência absoluta de citações, $\%=$ frequência relativa de citações. $\mathrm{N}$ total $=27$ entrevistados.

\begin{tabular}{|c|c|c|c|c|c|}
\hline \multirow{2}{*}{ Habitats pescadores } & \multicolumn{2}{|c|}{ robalo flecha } & \multicolumn{2}{|c|}{ robalo peva } & \multirow{2}{*}{ Habitat literatura } \\
\hline & $\mathbf{N}$ & $\%$ & $\mathbf{n}$ & $\%$ & \\
\hline Estruturas* & 17 & 63,0 & 11 & 40,7 & \multirow{3}{*}{$\begin{array}{l}\text { São eurialinos e suportam grandes variações de } \\
\text { salinidade (Figueiredo \& Menezes, 1980, Daros } \\
\text { et al., 2016), podendo viver em ambientes ma- } \\
\text { rinhos e dulcícolas (Mendonça, 2004). Quando } \\
\text { juvenis tendem a preferir águas doces e os adul- } \\
\text { tos habitam predominantemente ambientes com } \\
\text { grandes profundidades (Gilmore } \text { et al., 1983; } \\
\text { Nunes et al., 2015). }\end{array}$} \\
\hline Rio & 11 & 40,7 & 8 & 29,6 & \\
\hline Baixio & 3 & 11,1 & 3 & 11,1 & \\
\hline
\end{tabular}

* galhada, pedra, madeira, raiz.

FONTE: autores.

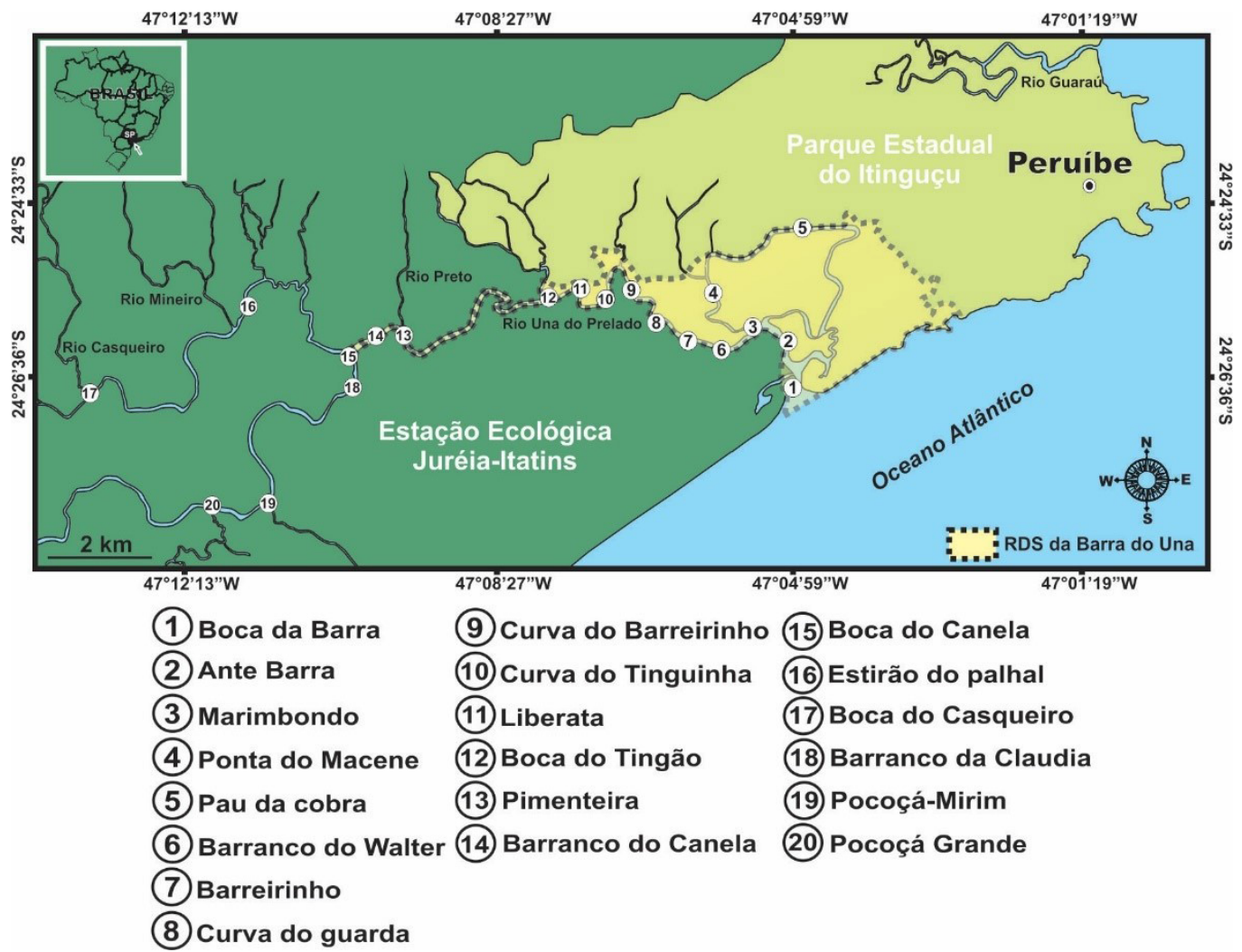

FIGURA 3 - Pesqueiros utilizados para a pesca esportiva na reserva de desenvolvimento sustentável da Barra do Una, Peruíbe (SP). FONTE: autores. 
Abundância e distribuições relativas do robalo são atribuídas a fatores como características físicas do habitat, salinidade e temperatura da água em áreas estuarinas (Winner et al. 2010). Assim como, no conhecimento local dos pescadores artesanais, onde a análise do uso de pesqueiros para a pesca esportiva apresentou padrões associados a especificidades dos habitats e parâmetros ambientais tais como: características dos pontos de pesca, salinidade, profundidade, amplitude de marés, sazonalidade e uso de iscas específicas

Quanto as características dos pontos mais utilizados são consideradas: a) "estruturas", nome dado a pedras, plantas, galhos ou árvores submersas (galhadas) onde geralmente os peixes procurados são encontrados; b) baixio, definido como banco de areia ou rochedo que fica submerso no mar ou rio; c) barranco (drop ou barrancão), sendo encosta ou desnível íngreme não coberta de vegetação; d) vegetação, principalmente aguapé e capim; e) saída de rio. Para a amplitude de maré são observadas a maré vazante (baixa-mar), e a maré enchente (preia-mar).

As iscas utilizadas podem ser naturais (camarão vivo, pitu, pedaços de peixes), o que requer disponibilidade para o fornecimento, ou artificiais. Estas últimas apresentam uma variedade de modelos, materiais, tamanhos e cores, sendo as principais: o Jig head (tipos de anzol com cabeça de chumbo onde se anexa um camarão de silicone), o Jumping jig (não flutuam e afundam, feitas em chumbo, utilizadas na pesca vertical produz movimentos de sobe desce), o Plug (iscas duras feitas em plásticos, imitam pequenos insetos e peixes em fuga) e a $S o f t$ bait (iscas moles, de materiais flexíveis, em silicone ou borracha).

Os pescadores mencionaram como preferência de alimentação dos robalos o consumo de camarões e peixes (Tabela 3 ). Segundo $85,2 \%$ dos pescadores não há diferença entre a alimentação de jovens e adultos, mas para 7,4\% os filhotes comem peixes pequenos, enquanto os adultos comem peixes maiores. Blewett et al. (2006) verificaram diferenças na dieta de pequenos robalos da Florida durante inverno e verão fortemente ligadas a seleção do tamanho das presas. A disponibilidade de presas de tamanho específico no estuário, influencia o consumo do robalo durante diferentes fases de sua ontogenia, bem como os tipos de presas que consomem sazonalmente. Segundo Tonini et al. (2007), os espécimes juvenis se alimentam preferencialmente de camarões, modificando sua dieta ao longo da vida.

A reprodução é um aspecto de difícil compreensão para os pescadores, a maioria (63\%) não soube explicar a forma como ocorre. Apenas 7,4\% dos entrevistados mencionou que soltam as "ovas" na água e 7,4\% indicaram que fazem ninhos perto de estruturas e soltam as ovas branca (macho) e amarela (fêmea) para misturar. Silvano e Begossi (2002) mostraram que, dentre vários aspectos de etnoictiologia, os pescadores apresentaram mais dúvidas em relação à reprodução dos peixes, o que pode se dar pela dificuldade de observação dos comportamentos subaquáticos também comuns em metodologias científicas.

Como não há dimorfismo sexual para a maioria dos peixes marinhos (Cerqueira et al., 2017), a diferenciação entre machos e fêmeas só é possível com a análise morfológica dos animais abatidos e abertos. Portanto, a maioria dos pescadores (33,3\%) indicou que não há diferenças entre machos e fêmeas e $18,5 \%$ apontou não saber como diferenciar. Além disso, Nunes et al. (2015) e Previate (2016) descreveram a protandria ou hermafroditismo protândrico como estratégia de reprodução dos robalos. 
Tabela 3 - Conhecimento local dos pescadores artesanais da Barra do Una sobre alimentação dos robalos. $\mathrm{N}=$ frequência absoluta de citações, $\%=$ frequência relativa de citações. $\mathrm{N}$ total $=27$ entrevistados.

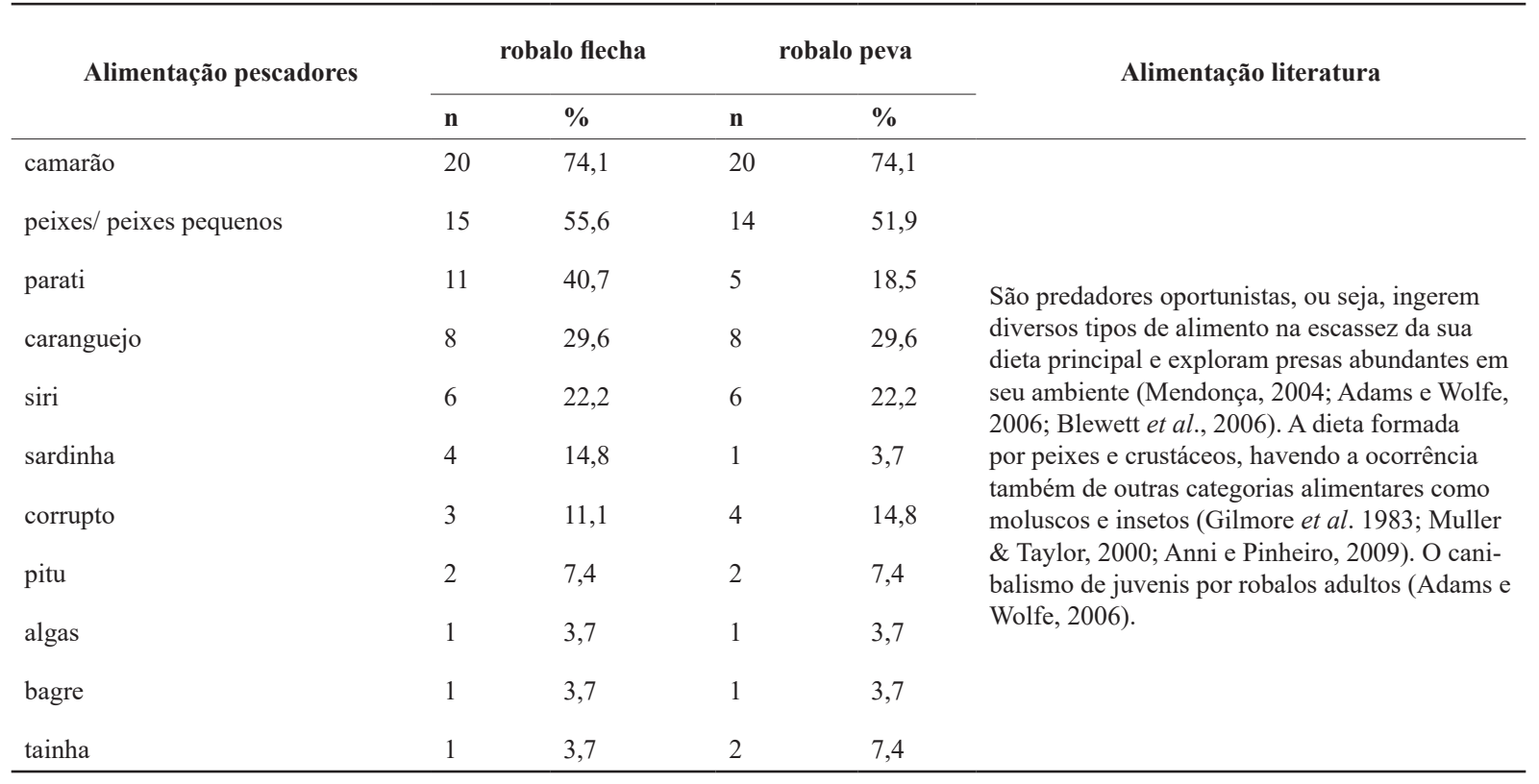

FONTE: autores.

Ou seja, inicialmente os órgãos masculinos atingem a maturidade e se tornam ativos, mas no processo de crescimento, as gônadas convertem-se em femininas e tornam-se ativas mais tarde, representando outro aspecto complexo da reprodução dos robalos, de difícil compreensão, tanto para a ciência, como para o conhecimento ecológicos local.

Os entrevistados citaram, em sua maioria (40,7\%), que os robalos sobem o rio para desovar (Tabela 4).

Segundo os pescadores, quando os robalos estão em trechos acima do rio (mais distantes da foz), apresentam coloração mais escura, fato associado a reprodução. A justificativa dos pescadores para esta observação é a de que se mantivessem coloração clara no rio, se tornariam presa fácil e não conseguiriam se reproduzir. Quanto a suscetibilidade à predação, Adams et al. (2012) relatou que quando a temperatura da água atinge valores próximos de $12,5^{\circ} \mathrm{C}$, o robalo torna-se muito letárgico e perde um pouco de sua mobilidade, tornando-os assim mais suscetível à predação, como estratégia se move para outros locais, mas informações sobre a mudança de coloração associada a esta movimentação não estão disponíveis em trabalhos científicos da região.

Quanto ao período reprodutivo, os pescadores artesanais apontaram que os robalos se reproduzem com maior frequência durante o verão (Figura 04). Esta informação corrobora ao observado por Teixeira (2020) para C. parallelus, no mesmo estuário 
TABELA 4 - Locais de reprodução dos robalos segundo os pescadores artesanais da Barra do Una. $\mathrm{N}=$ frequência absoluta de citações, $\%=$ frequência relativa de citações. $\mathrm{N}$ total $=27$ entrevistados.

\begin{tabular}{|c|c|c|c|c|c|}
\hline \multirow[t]{2}{*}{ Local de reprodução } & \multicolumn{2}{|c|}{$\begin{array}{l}\text { C. undecimalis } \\
\text { robalo flecha }\end{array}$} & \multicolumn{2}{|c|}{$\begin{array}{l}\text { C. parallelus } \\
\text { robalo peva }\end{array}$} & Literatura científica \\
\hline & $\mathbf{n}$ & $\%$ & $\mathbf{n}$ & $\%$ & \multirow{6}{*}{$\begin{array}{l}\text { Na Florida, estudos apontavam que a desova ocorre } \\
\text { no ambiente marinho (Gilmore et al., 1983). No en- } \\
\text { tanto, foram registrados indicativos de que o gatilho } \\
\text { para desova dos robalos é a mistura entre a água } \\
\text { do médio estuário com as águas do baixo estuário } \\
\text { (Taylor } \text { et al., 2000). Na região Nordeste do Brasil, } \\
\text { foram encontradas fêmeas com característica de } \\
\text { desova no ambiente estuarino (Mendonça, 2004). }\end{array}$} \\
\hline rio/ sobe o rio & 11 & 40,7 & 11 & 40,7 & \\
\hline costeira/ mar & 3 & 11,1 & 3 & 11,1 & \\
\hline água parada, calma & 3 & 11,1 & 3 & 11,1 & \\
\hline mangue & 2 & 7,4 & 1 & 3,7 & \\
\hline entrada de rio & 1 & 3,7 & 1 & 3,7 & \\
\hline
\end{tabular}

FONTE: autores.

e período amostral deste estudo. Porém, difere de Rodrigues (2005) que observou o período reprodutivo do robalo peva entre março e agosto, no estuário do Rio Doce - ES. Assim, embora os dois estudos supracitados estejam localizados na região sudeste do Brasil, fica evidenciada uma diferenciação regional dos parâmetros reprodutivos. Como discutido anteriormente, a influência das variáveis abióticas também influencia nos aspectos reprodutivos de Centropomidae, que embora suportem amplas variações de salinidade (Alvarez-Lajonchère e Tsuzuki, 2008), apresentam características diferenciadas durante as estações climáticas, como observado por Lorán-Núñez et al. (2012) no México, Chaves e Nogueira (2013) na Baía de Guaratuba - PR e Cruz-Botto et al. (2018) no de Santa Marta - Colômbia.

É importante ressaltar que o período reprodutivo observado por Teixeira (2020) e indicado pelos pescadores, coincide com o período de maior captura destas espécies na região
(Souza, 2019). Assim, são necessários programas educativos e medidas de gestão que contemplem a pesca artesanal e esportiva para evitar sobreexploração das espécies, como já indicado por Silvano et al. (2014), Gassman et al. (2017) e Garrone-Neto et al. (2018), que avaliaram diferentes medidas de conservação para os robalos.

\subsection{Ordenamento da pesca esportiva na Reserva de Desenvolvimento Sustentável da Barra do Una}

Os pescadores artesanais demandam ações para que a atividade da pesca esportiva seja ordenada e se torne mais importante para renda e sustentabilidade local. Com as informações obtidas através das contribuições dos pescadores artesanais e as informações técnico-científicas da literatura foram apresentadas recomendações para o ordenamento da pesca esportiva na RDS Barra do Una (Tabela 5). 
Alguns instrumentos importantes para a gestão da atividade pesqueira em geral, são regulamentados por legislação específica. A instrução normativa MMA 53/2005 define o tamanho mínimo para captura das espécies. A Portaria IBAMA n ${ }^{\circ}$ 4/ 2009 estabeleceu a necessidade das licenças para pesca e respectivas regras para a pesca esportiva. A instrução normativa MPA 05/2012 normatiza as competições de pesca e seus requisitos legais. A instrução normativa interministerial MPA/MMA 09/2012, estabeleceu as normas gerais para o exercício da pesca esportiva em todo o território nacional, incluindo o uso do seu produto e outros detalhamentos. Seu art. $2^{\circ}$. não permite comercialização, prevendo o consumo, ornamentação, obtenção de isca viva ou pesque-solte. $\mathrm{O}$ art. $5^{\circ}$ apresenta os petrechos permitidos. Os artigos $6^{\circ}$ e $7^{\circ}$ apresentam os limites de captura em peso e unidades em águas marinhas e continentais. Os artigos $8^{\circ}$ e $9^{\circ}$ estabelecem os tipos de transporte permitidos, armazenamento e definem as embarcações permitidas. Já a Portaria MMA N445/ 2014 classifica e elenca as espécies de peixes e invertebrados aquáticos ameaçados de extinção, que são protegidas de modo integral sendo proibidas sua captura, transporte, armazenamento, guarda, manejo, beneficiamento e comercialização.

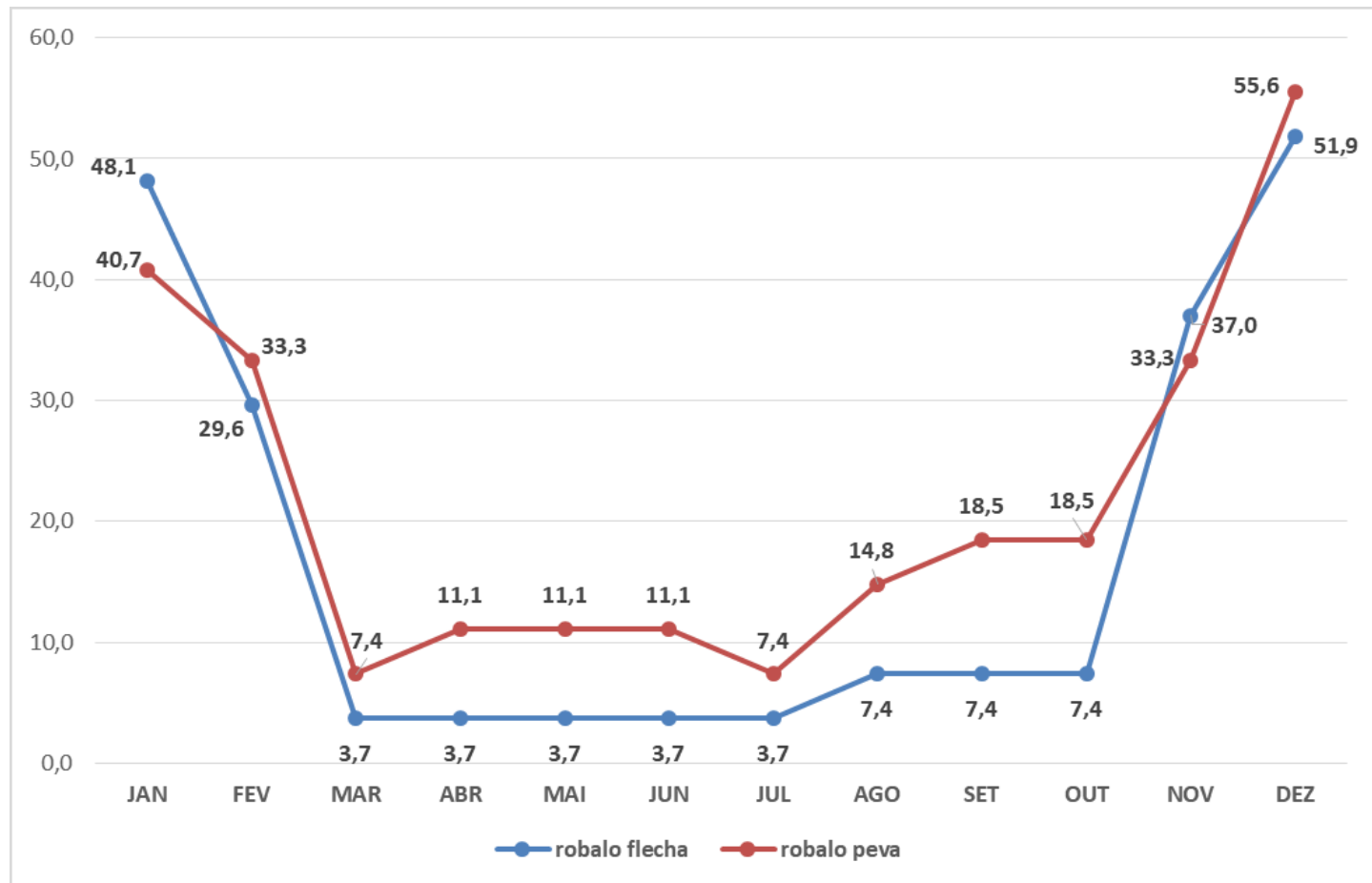

FIGURA 4 - Época de reprodução dos robalos, segundo os pescadores artesanais da reserva de desenvolvimento sustentável da Barra do Una, Peruíbe (SP).

NOTA: Os valores correspondem a porcentagem de citação das informações nas entrevistas.

FONTE: autores. 
TABELA 5 - Recomendações para o ordenamento da pesca esportiva na reserva de desenvolvimento sustentável da Barra do Una (SP).

FAO $(2012,2013)$

A prática do pesque-e-solte é realizada como uma medida de conservação dos peixes, seu objetivo é o lazer, sendo uma forma de garantir a reprodução das espécies. Cuidados com o meio ambiente, respeito às comunidades locais, atenção no manuseio do pescado, conformidade com a legislação são atitudes relacionadas às boas práticas, exercidas pelos pescadores esportivos, e todos os atores e usuários dos recursos pesqueiros.

O conhecimento e percepção das comunidades contribui para o diagnós-

Envolvimento da população local

Atuação do conselho gestor

Integração com outras UC's

Parcerias público/ privadas

\section{Monitoramento}

Comunicação

Pesquisa científica tico e a solução de problemas sociais, econômicos, culturais e políticos. A atuação dos guias de pesca representa uma estratégia pesqueira fundamental para os praticantes da pesca esportiva.

Fomentar o fortalecimento do conselho gestor da UC, criar espaços para as discussões específicas sobre o ordenamento da pesca esportiva. Incentivar a criação e/ou o fortalecimento de instituições para representação dos pescadores esportivos para melhorar os canais de diálogo.

Fortalecer a integração da Reserva de Desenvolvimento Sustentável da Barra do Una com outras UCs visando a cogestão da atividade, integrando interesses e informações.

Parcerias entre poder público, iniciativa privada, terceiro setor, trabalho de forma articulada com a comunidade local, pescadores esportivos e demais usuários. Realização de ações, programas e projetos integrados.

Parceria com instituições financiadoras de projetos ambientais com

A coleta de informações sobre a prática da pesca esportiva como instrumento de gestão para tomadas de decisão. Criação de sistema de cadastramento das embarcações que prestam serviços à pesca esportiva, relatórios de pescarias, sistema de coleta de informações junto aos pescadores esportivos (número de pescadores no grupo, pontos de pesca, iscas utilizadas, peixes capturados (peso), tamanhos, número de peixes soltos e abatidos etc.) informações que auxiliem pesquisas sobre a pressão exercida pela atividade.

Divulgação de informações, regulamentações, normas, leis referentes à: espécies proibidas, tamanhos mínimos de captura, defesos, locais proibidos, equipamentos proibidos e licenças para a pesca.

Parcerias com universidades, fundações e instituições de pesquisa, aprofundar conhecimento das interferências da pesca no equilíbrio costeiro/ marinho, avaliação da capacidade de suporte do recurso pesqueiro, dentre outras lacunas de conhecimento, fortalecimento da gestão e seus instrumentos, como Plano de Manejo. linhas de ações específicas para demandas.
Brownscombre et al. (2019)

Ceccarelli (2006)

Cooke \& Cowx (2004)

Arlinghaus et al. (2010)

Encontro Nacional da Pesca Amadora (2010)

FAO (2012)

São Paulo (2014)

Amazonas (2009)

São Paulo (2014)

Sales (2012)

São Paulo (2014)

Encontro nacional da pesca amadora (2010)

São Paulo (2014)

Demandas da população local e da gestão da RDS

São Paulo (2014)

Teramoto e Diegues (2014)

Barrella et al. (2016)

Amazonas (2009)

São Paulo (2014) 
Ações conjuntas entre os órgãos de fiscalização e agentes comunitários ou da equipe de gestão da UC poderiam ser planejadas. Ações em temporadas de pesca, finais de semana, férias e feriados. Incremento e criação de inteligência efetiva na fiscalização. Ampliar a fiscalização do porte de licença de pesca, espécies, limites, cotas e locais permitidos pela legislação.

Programas de capacitação para gestores, tomadores de decisão, atores envolvidos, como suporte para a solução de problemas e conflitos na gestão da UC e ordenamento da atividade.
Amazonas (2009)

São Paulo (2014)

Encontro nacional da pesca amadora (2010)

São Paulo (2014)

FONTE: autores.

Sobrepondo-se a esta última temos o Decreto Estadual no 60.133/2014 que classifica as espécies e seus níveis de proteção; proíbe a captura e comercialização do Cherne-poveiro (Polyprion americanus). Dentre outras especificas para alguns recursos, como a portaria interministerial MPA/MMA $\mathrm{N}^{\circ} 13 /$ 2015 que proíbe a captura do mero (Epinephelus itajara) por mais 8 anos.

A gestão pesqueira é essencial para a sustentabilidade dos recursos, preservando a manutenção de seus estoques. Neste sentido, destacamos a importância do papel dos pescadores para o monitoramento, incluindo o fornecimento de dados sobre a abundância e captura dos peixes, o incentivo as boas práticas (como o pesque e solte, por exemplo), orientação sobre os locais permitidos ou proibidos para a pesca, bem como a participação efetiva em fóruns de discussão sobre a gestão da pesca, especialmente o conselho gestor da UC, visando o uso sustentável como contribuição para a conservação dos recursos pesqueiros (Brownscombe et al., 2019). Neste sentido, o monitoramento da pesca esportiva, na RDSBU, poderia ser realizado através de um esforço conjunto entre a gestão da UC, os guias de pesca locais e pescadores esportivos. No
Brasil, assim como sugerido em outros países, há necessidade de se estabelecer um banco de dados de captura para a pesca esportiva, abrangendo dados além dos biológicos, como, por exemplo, os correlacionados, como esforço de captura e socioeconômicos (Brownscombe et al., 2014).

A coleta de dados sistemática sobre os estoques e a práticas da pesca esportiva, são essenciais às estratégias e desenvolvimento de pesquisas para embasar as políticas governamentais e legislação específica. No Brasil, considerando sua grande extensão territorial e um vasto número de espécies e locais diferenciados de pesca, o que se tem atualmente são ações que precisam estar congruentes, integradas. Assim, de maneira geral, é importante a identificação dos desafios e oportunidades para a coleta de dados e diagnóstico das principais lacunas de pesquisa e questões de gestão (Pita et al., 2017).

É essencial observarmos toda a complexidade envolvida no caso da pesca esportiva para contribuir nas abordagens de gestão e ordenamento. A pesca esportiva deve ser ordenada por procedimentos que se apoiem em critérios que sejam ecológicos e socialmente orientados, tendo como base pesquisas locais que englobem suas complexidades específi- 
cas, com vistas a potencialidades e benefícios, tanto para os moradores locais quanto aos pescadores esportivos (Barnett et al., 2016).

Outro aspecto importante a ser levado em consideração é que a captura de espécies e as regulamentações da pesca esportiva precisam ser revisadas tendo em conta a capacidade das espécies de ultrapassar as fronteiras políticas entre os estados, regiões e outras Unidades de Conservação. Mais recentemente, discussões neste sentido fomentaram a criação da Portaria MMA/ICMBIO nº 91/2020, que dispõe sobre procedimentos para a normatização da atividade de pesca esportiva em UCs federais, com o intuito de gerar instrumentos legais para o ordenamento da atividade e previsão em planos de manejo. Esta portaria enfatiza a prática em UCs de categorias de uso sustentável, no entanto, também contempla a realização da pesca esportiva em UCs de proteção integral, que abriguem em seu território populações tradicionais, através de regulamentação por Termos de Compromisso. A exemplo desta inciativa federal, os órgãos gestores, responsáveis pelas UCs estaduais, tem a possibilidade de criar mecanismos, semelhantes e adaptados, para a normatização da pesca esportiva em suas áreas. Em especial, para os mosaicos de UC, como o Mosaico Jureia-Itatins, o qual a RDS Barra do Una faz parte, que são formados por áreas limítrofes, com diferentes níveis de restrição de uso, mas que abrigam ambientes aquáticos, semelhantes e contínuos, com potencial para a prática da pesca esportiva, de maneira ordenada e visando a sustentabilidade dos recursos compartilhados entre as UCs de cada mosaico.

Garrone Neto et al. (2018), por exemplo, fizeram uma avaliação importante dos instrumentos de gestão e apontaram aspectos positivos e negativos da legislação vigente entre os estados do Paraná e São Paulo, com base em seus resultados sobre captura e recaptura de robalos. Alguns aspectos positivos foram indicados para a legislação do estado do Paraná que poderiam ser analisados para São Paulo, como adoção de tamanhos máximos de captura para $C$. parallelus de $50 \mathrm{~cm}$ e $C$. undecimalis de $70 \mathrm{~cm}$, regulamentada pela RS CEMA PR $91 / 2013$. Além disso, a gestão pesqueira é baseada em avaliações em aspectos biológicos, como abundância ou idade, informações da história de vida dos peixes, alimentação e reprodução, entre outras informações fornecidas por pesquisa científica capaz de contribuir para essas avaliações e podem ser usadas pelos gestores para iniciar medidas de conservação apropriadas a unidade de conservação (Peters et al., 1998).

É imprescindível, também, a existência de um canal de comunicação entre o poder público, comunidades de pescadores e o setor turístico de pesca esportiva, assim como, de todos os usuários, no que diz respeito às políticas públicas a serem aplicadas, a longo e médio prazo, objetivando o turismo de pesca de mínimo impacto e observando a sustentabilidade do meio biótico (Menezes et al. 2013).

\section{Considerações finais}

A pesca esportiva representa uma alternativa de renda para as famílias de pescadores artesanais da Reserva de Desenvolvimento Sustentável da Barra do Una, que aplicam seus conhecimentos pesqueiros nesta prática. O que pode ser confirmado, através da análise do conhecimento ecológico local acerca dos robalos, principal alvo da pesca 
esportiva, mostrando-se detalhado e, considerado como a principal contribuição deste trabalho, para ampliar o conhecimento sobre os robalos e a atividade de pesca esportiva na RDS. Além disso, os pescadores locais trouxeram sugestões e demandas para o ordenamento da pesca esportiva, que vieram de encontro com as informações disponíveis nos materiais técnicos consultados e, que puderam ser analisados, de maneira integrada, e sistematizados para a proposição de recomendações para o ordenamento da pesca esportiva na RDS Barra do Una.

Os resultados alcançados demonstram que uma gestão participativa é desejável e deve promover a interação entre os usuários, levando o pescador esportivo a valorizar e apoiar a pesca, respeitar o pescador artesanal e o ambiente, contribuindo assim, para melhorar o atendimento à demanda do setor e garantir a sustentabilidade ambiental e socioeconômica.

As recomendações expressas neste trabalho, possuem potencial de aplicação na RDS Barra do Una, uma vez que apontam um conjunto de ferramentas para resolução dos problemas de pesca, particularmente incluindo o conhecimento dos principais usuários como um dos métodos de pesquisa científica utilizados.

Por fim, durante a finalização deste trabalho, as informações foram utilizadas para a elaboração de um Plano de Utilização dos recursos naturais da RDS Barra do Una. Espera-se que as recomendações geradas também sejam utilizadas, oportunamente, na produção do Plano de Manejo e, em futuras discussões, sobre o manejo integrado das demais Unidades de Conservação do Mosaico Jureia-Itatins.

\section{Agradecimentos}

Agradecemos ao $\mathrm{CNPq}$ pelo financiamento, aos pescadores artesanais da RDS Barra do Una, à gestão da UC e à Amanda Carminato pelas contribuições.

\section{Referências}

Adams, A. J.; Hill, J. E.; Kurth, B. N.; Barbour, A. B. Effects of a severe cold event on the subtropical, estuarine-dependent common snook, Centropomus undecimalis. Gulf and Caribbean Research, 24(1), 13-21, 2012. doi: 10.18785/ gcr.2401.03

Adams, A. J.; Wolfe, R. K. Cannibalism of juveniles by adult common snook (Centropomus undecimalis). Gulf of Mexico Science, 24(1), 11-13, 2006. Disponível em: http://208.106.199.251/research/Adams\%20and\%20 Wolfe\%20GOMS\%202006\%20snook.pdf

Alvarez-Lajonchère, L.; Tsuzuki, M. Y. A review of methods for Centropomus spp. (snooks) aquaculture and recommendations for the establishment of their culture in Latin America. Aquaculture Research, 39(7), 684-700, 2008. doi: 10.1111/j.1365-2109.2008.01921.x

Amazonas. Plano de uso para a pesca esportiva da Reserva de Desenvolvimento Sustentável do Uatumã - PUPE / RDSU, 2009. Disponível em: $<$ https://idesam.org/publicacao/plano-pesca-esportiva-rdsu.pdf $>$. Acesso em: jun. 2020.

Anni, I. S. A.; Pinheiro, P. C. Hábito alimentar das espécies de robalo Centropomus parallelus Poey, 1986 e Centropomus undecimalis (Bloch, 1792) no litoral norte de Santa Catarina e sul do Paraná, Brasil. In: Anais do III Congresso Latino Americano de Ecologia. São Çourenço, 10-13 de set., 2009. Disponível em: http://ecologia.ib.usp. br/seb-ecologia/2009/resumos_clae/39.pdf

Arlinghaus, R.; Cooke, S. J.; Cowx, I. G. Providing context to the global code of practice for recreational fisheries. Fisheries Management and Ecology, 17, 146-156, 2010. doi: 10.1111/j.1365-2400.2009.00696.x 
Arlinghaus, R.; Cooke, S. J.; Sutton, S. G.; Danylchuk, A. J.; Potts, W.; Freire, M. F.; Alós, J.; Da Silva, E.T.; Cowx, I.G.; Van Anrooy, R. Recommendations for the future of recreational fisheries to prepare the social-ecological system to cope with change. Fisheries Management and Ecology, 23(3-4), 177-186, 2016. doi: 10.1111/fme.12191

Barcellini, V. C.; Motta, F. S.; Martins, A. M.; Moro, P. S. Recreational anglers and fishing guides from an estuarine protected area in southeastern Brazil: Socioeconomic characteristics and views on fisheries management. Ocean e Coastal Management, 76, 23-29, 2013. doi: 10.1016/j. ocecoaman.2013.02.012

Barletta, M.; Barletta-Bergan, A.; Saint-Paul, U.; Hubold, $\mathrm{G}$. The role of salinity in structuring the fish assemblages in a tropical estuary. Journal of Fish Biology, 66, 45-72, 2005. doi: 10.1111/j.0022-1112.2005.00582.x

Barnett, A.; Abrantes, K. G.; Baker, R.; Diedrich, A. S.; Farr, M.; Kuilboer, A.; Mahony, T.; Mcleod, I.; Moscardo, G.; Prideaux, M.; Stoeckl, N.; Van Luyn, A.; Sheaves, M. Sportfisheries, conservation and sustainable livelihoods: a multidisciplinary guide to developing best practice. Fish and Fisheries, 17(3), 696-713, 2016. doi: 10.1111/faf.12140

Barrella, W.; Ramires, M.; Rotundo, M. M.; Petrere Jr, M.; Clauzet, M.; Giordano, F. Biological and socio-economic aspects of recreational fisheries and their implications for the management of coastal urban areas of south-eastern Brazil. Fisheries Management and Ecology, 23, 1-12, 2016. doi: 10.1111/fme. 12173

Bennett, N. J. Using perceptions as evidence to improve conservation and environmental management. Conservation Biology, 30, 582-592, 2016. doi: 10.1111/cobi.12681

Berkes, F. Adaptive co-management and complexity: Exploring the many faces of co-management. In: Armitage, D; Berkes, F e Doubleday, N. (Eds.). Adaptive co-management: collaboration, learning, and multi-level governance. University of British Columbia Press, 19-37, 2007.

Bernard, H. R. Research methods in anthropology: qualitative and quantitative approaches. Maryland: Rowman e Littlefield, 6. ed, 2017.

Blewett, D. A.; Hensley, R. A.; Stevens, P. W. Feeding habits of common snook, Centropomus undecimalis, in Charlotte
Harbor, Florida. Gulf and Caribbean Research, 18(1), 1-14, 2006. doi: $10.18785 /$ gcr.1801.01

Brownscombe, J. W.; Bower, S. D.; Bowden, W.; Nowell, L.; Midwood, J. D.; Johnson, N.; Cooke, S. J. Canadian recreational fisheries: 35 years of social, biological, and economic dynamics from a national survey. Fisheries, 39, 251-260, 2014. doi: 10.1080/03632415.2014.915811

Brownscombe, J. W.; Hyder, K.; Potts, W.; Wilson, K. L.; Pope, K. L.; Danylchuk, A. J.; Cooke, S. J.; Clarke, A.; Arlinghaus, R.; Post, J.R. The future of recreational fisheries: Advances in science, monitoring, management, and practice. Fisheries Research, 211, 247-255, 2019. doi: 10.1016/j.fishres.2018.10.019

Castello, J. P. Gestão sustentável dos recursos pesqueiros, isto é realmente possível. Pan-American Journal of Aquatic Sciences, 2(1), 47-52, 2007. Disponível em: https://panamjas.org/artigos.php?id_publi=128

Catella, A. C.; Mascarenhas, M. R.; Albuquerque, S. P.; Albuquerque, F. F.; Theodoro, E. R. M. Sistemas de estatísticas pesqueiras no Pantanal, Brasil: aspectos técnicos e políticos. Pan-American Journal of Aquatic Sciences, 3(3), 174-192, 2008. Disponível em: https://panamjas.org/pdf_conteudos/ PANAMJAS_3(3)_174-192.pdf

Ceccarelli, P. S. Pesque-e-solte: informações gerais e procedimentos práticos. Brasília: Ibama, 2006. Disponível em: <www.ibama.gov.br/sophia/cnia/livros/pesqueesolte.pdf.> Acesso em: fev., 2019.

Cerqueira, V. R.; Carvalho, C. V. C.; Sanches, E. G.; Passini, G.; Baloi, M.; Rodrigues, R. V. Manejo de reprodutores e controle da reprodução de peixes marinhos da costa brasileira. Revista Brasileira de Reprodução Animal, 41, 94-102, 2017. Disponível em: http://cbra.org.br/portal/downloads/ publicacoes/rbra/v41/n1/p094-102\%20(RB677).pdf

Chaves, P. T.; Nogueira, A. B. Influência da salinidade no desenvolvimento e relação peso-comprimento do robalo-peva. Boletim do Instituto de Pesca, 39(4), 423-432, 2013.

Cooke, S. J.; Cowx, I. G. The role of recreational fishing in global fish crises. Bioscience, 54, 857-859, 2004. doi: 10.1641/0006-3568(2004)054[0857:TRORFI]2.0.CO;2

Cooke, S. J.; Hogan, Z. S.; Butcher, P. A.; Stokesbury, M. 
J.; Raghavan, R.; Gallagher, A. J.; Hammerschlag, N.; Danylchuk, A. J. Angling for endangered fish: conservation problem or conservation action? Fish and Fisheries, 17(1), 249-265, 2016. doi: 10.1111/faf.12076

Cowx, I.G.; Arlinghaus, R.; Cooke, S. J. Harmonizing recreational fisheries and conservation objectives for aquatic biodiversity in inland waters. Journal of Fish Biology, 76, 2194-2215, 2010. doi: 10.1111/j.1095-8649.2010.02686.x

Cruz-Botto, S.; Roca-Lanao, B.; Gaitán-Ibarra, S.; Chaparro-Muñoz, N.; Villamizar, N. Natural vs laboratory conditions on the reproductive biology of common snook Centropomus undecimalis (Bloch, 1792). Aquaculture, 482, 9-16, 2018. doi: 10.1016/j.aquaculture.2017.09.013

Dalton, T.; Pollnac, R.; Forrester, G. Investigating causal pathways linking site-level characteristics, compliance, and ecological performance in Caribbean MPAs. Coastal Management, 43, 329-341, 2015. doi: 10.1080/08920753.2015.1030332

Daros, F. A.; Spach, H. L.; Correia, A. T. (2016). Habitat residency and movement patterns of Centropomus parallelus juveniles in a sub- tropical estuarine complex. Journal of Fish Biology, 88(5), 1796-1810, 2016. doi: 10.1111/ jfb. 12944

Davis, A.; Wagner, J. R. Who knows? On the importance of identifying "experts" when researching local ecological knowledge. Human Ecology, 31(3), 463-489, 2003. Disponível em: https://link.springer.com/article/10.1023/A:1025075923297

Encontro Nacional da Pesca Amadora. "Construindo a Política da Pesca Amadora”. Ministério da Pesca e Aquicultura, 2010. Disponível em: <pt.slideshare.net/zezinhocoimbra/ 1-encontro-amador-de-pesca $>$ Acesso em: fev., 2019.

Evans, L.; Hicks, C. C.; Cohen, P. J.; Case, P.; Prideaux, M.; Mills, D. J. Understanding leadership in the environmental sciences. Ecology and Society, 20(1), 7-9, 2015. Disponível em: https://www.jstor.org/stable/26269759?seq=1\#metadata_info_tab_contents

FAO - Food and Agriculture Organization. Technical Guidelines for Responsible Fisheries. Recreational Fisheries, 13, 2012. Disponível em: http://www.fao.org/docrep/016/ i2 $708 \mathrm{e} / \mathrm{i} 2708 \mathrm{e} 00 . \mathrm{htm}$
FAO- Food and Agriculture Organization. State of food insecurity in the world 2013: the multiple dimensions of food security, 2013. Disponível em: <https://reliefweb.int/ sites/reliefweb.int/files/resources/State of Food Insecurity in the World \%28SOFI 2013\%29.pdf $>$. Acesso em: jan. 2019.

Figueiredo, J.L.; Menezes, N.A. Manual de peixes marinhos do sudeste do Brasil: III. Teleostei (2). São Paulo: Museu de Zoologia (USP), 1980.

Freire, K. M. F. Unregulated Catches from Recreational Fisheries Off Northeastern Brazil. Atlântica, 32, 87-93, 2010. Disponível em: http://repositorio.furg.br/handle/1/446

Garrone Neto, D.; Sanches, E. A.; Daros, F. A. L. D. M.; Imanobu, C. M. R.; Moro, P. S. Using the same fish with different rules: A science-based approach for improving management of recreational fisheries in a biodiversity hotspot of the Western South Atlantic. Fisheries management and ecology, 25(4), 253-260, 2018. doi: 10.1111/fme.12288

Gassman, J.; López-Rojas, H.; Padrón, D. Reproducción de los róbalos Centropomus undecimalis y C. ensiferus (Perciformes: Centropomidae) en una laguna costera tropical. Revista de Biología Tropical, 65(1),181-194, 2017.

Gilmore, R. G.; Donahoe, C. J.; Cooke, D. W. Observations on the distribution and biology of the common snook, Centropomus undecimalis (Bloch). Florida Scientist. 46, 313-336, 1983. Disponível em: https://www.jstor.org/stable/24320342?seq=1

Granek, E. F.; Madin, E. M.; Brown, M. A.; Figueira, W.; Cameron, D. S.; Hogan, Z.; Kristianson, G.; De Villiers, P.; Williams, J. E.; Post, J.; Zahn, S.; Arlinghaus, R. Engaging recreational fishers in management and conservation: global case studies. Conservation Biology, 22(5), 1125-1134, 2008. doi: 10.1111/j.1523-1739.2008.00977.x

Johannes, R. E; Freeman, M. M. R.; Hamilton, J. R. Ignore fishers' knowledge and miss the boat. Fish and Fisheries, 1, 257-271, 2000. doi: 10.1111/j.1467-2979.2000.00019.x

Kroloff, E. K.; Heinen, J. T.; Braddock, K. N.; Rehage, J. S.; Santos, R. O. Understanding the decline of catch-and-release fishery with angler knowledge: a key informant approach applied to South Florida bonefish. Environmental Biology of Fishes, 102(2), 319-328, 2019. Disponível em: https://link. springer.com/article/10.1007/s10641-018-0812-5 
Lorán-Núñez, R. M.; Martínez-Isunza, F. R.; Valdez-Guzmán, A. J.; Garduño-Dionate, M.; Martínez-Lorán, E. R. Reproducción y madurez sexual de robalo prieto (Centropomus poeyi) y robalo blanco (C. undecimalis) en el Sistema Lagunar de Alvarado, Veracruz (2005-2007). Ciencia Pesquera, 20(1), 49-64, 2012.

Marques, J. G. W. Pescando pescadores: ciência e etnociência em uma perspectiva ecológica. São Paulo: NUPAUB/ USP, $2^{\mathrm{a}}$ ed., 2001.

Mendonça, J.T.; Katsuragawa, M. Caracterização da pesca artesanal no complexo estuarino-lagunar de Cananéia-Iguape, Estado de São Paulo, Brasil (1995-1996). Acta Scientiarum. Biological Sciences, 23, 535-547, 2001. doi: 10.4025/actascibiolsci.v23i0.2713

Mendonça, M. C. F. B. Autoecologia do camorim, Centropomus undecimalis (Bloch, 1792), (Perciformes: Centropomidae) em ambiente hipersalino em Galinhos, $R N$, Brasil. São Carlos, Tese (Doutorado em Ecologia e Recursos Naturais) - UFSCar, 2004. Disponível em: https://repositorio.ufscar. br/handle/ufscar/1883

Menezes, A. A. S.; Lin, C. F.; Silva, C.; Dos Santos, R. A. Aspectos socioeconômicos relacionados à pesca amadora de robalo (Centropomus undecimalis e C. parallelus) na Baía da Babitonga, Santa Catarina, Brasil. Revista CEPSUL Biodiversidade e Conservação Marinha, 3(1), 22-44, 2013. doi: 10.37002/revistacepsul.vol3.33322-44

Molitzas, R.; Souza, U. P.; Rotundo, M. M.; Sanches, R. A.; Barrella, W.; Ramires, M. Avaliação temporal dos sistemas pesqueiros na Reserva de Desenvolvimento Sustentável de Barra do Una (Peruíbe/SP). Revista GeoInterações, 3(1), 3-25, 2019.

Motta, F. S.; Mendonça, J. T.; Moro, P. S. Collaborative assessment of recreational fishing in a subtropical estuarine system: a case study with fishing guides from south-eastern Brazil. Fisheries Management and Ecology, 23(3), 291-302, 2016. doi: 10.1111/fme.12172

Muller, R. G.; Taylor, R. G. The Stock assessment update of common snook, Centropomus undecimalis. Florida Marine Research Institute, 2000.

Nora, V. Ecologia e etnoecologia de robalos (Centropomus undecimalis (Bloch 1792) e Centropomus parallelus Poey
1860) na Baía de Paraty, RJ, Brasil. Santos, Dissertação (Mestrado em Ecologia) - UNISANTA, 2013. Disponível em: http://unisanta.br/Download/Download?NomeDoArquivoOriginal $=$ mestrado $\% 5$ Cecologia $\% 5$ Cdissertacoes $\%$ 5CDissertacao_Mariana.pdf

Nunes, Z. M. P., Pereira, M. E. G. S.; Da Silva, B. B.; Da Rocha, R. M.; Asp-Neto, N. E.; Da Silva, C. S. Bioecologia do robalo-flexa, Centropomus undecimalis, em lagoa costeira tropical no norte do Brasil. Boletim do Instituto de Pesca, 41(3), 457-469, 2015. Disponível em: https://www.pesca. sp.gov.br/boletim/index.php/bip/article/view/41_3_457-469

Pereira, J. M. A.; Petrere-Jr, M.; Ribeiro-Filho, R. A. Angling Sport fishing in Lobo-Broa reservoir (Itirapina, SP, Brazil). Brazilian Journal of Biology, 68(4), 721-731, 2008. doi: 10.1590/S1519-69842008000400006

Peters, K. M.; Matheson JR, R. E.; Taylor, R. G. Reproduction and early life history of common snook, Centropomus undecimalis (Bloch), in Florida. Bulletin of Marine Science, 62(2), 509-529, 1998.

Pinto, J.R.D.S.; Araújo, M.L.G.; Rosa, R.A.; Santos, J.P.; Araujo, A.R.D.R.; Barbosa, J.M. Espacialização das capturas de robalo (Centropomus spp.) (Centropomidae-Perciformes) no estuário do Rio Sergipe. Arquivo de Ciências do Mar, 51(2): 72-83, 2018. doi: 10.32360/acmar.v51i2. 33177

Pita, P.; Artetxe, I.; Diogo, H.; Gomes, P.; Gordoa, A.; Hyder, K.; Pereira, J.; Pita, C.; Rangel, M.; Garcia-Rodrigues, J.; Saguél, O.; Veiga, P.; Vingada, J.; Villasante, S. Research and management priorities for Atlantic marine recreational fisheries in Southern Europe. Marine Policy, 86, 1-8, 2017.

Prado, D. O. P.; Ramires, M. Resgate do conhecimento etnozooterápico da Comunidade Barra do Una (Peruíbe-SP). Research, Society and Development, 9(12), 1-22, 2020. doi: 10.33448/rsd-v9i12.6111

Prado, D. P.; Zeineddine, G. C.; Vieira, M. C.; Barrella, W.; Ramires, M. Preferências, tabus alimentares e uso medicinal de peixes na reserva de Desenvolvimento sustentável Barra do Una, São Paulo. Ethnoscientia, 2(1), 1-15, 2017. doi: 10.22276/ethnoscientia.v2i1.84

Previate, I. Uso de habitat e padrão de movimento de Centropomus parallelus (N.V. Robalo-peva) no complexo estuarino de Paranaguá, Estado do Paraná, Sul do Brasil. 
Curitiba, Dissertação (Mestrado em Ecologia e Conservação) - Universidade Federal do Paraná, 2016.

Raupp, F. M.; Beuren, I. M. Metodologia da pesquisa aplicável às ciências sociais. In: Beuren, I. M. (Org.). Como elaborar trabalhos monográficos em contabilidade: teoria e prática. 2. ed. São Paulo: Atlas, p.76-97, 2004.

Rodrigues, P. P. Aspectos reprodutivos do robalo peba, Centropomus parallelus, na foz do rio doce, Linhares/ES. Vitória, Monografia (Graduação em Oceanografia)-UFES, 2005. Disponível em: http://www.oceanografia.ufes.br/sites/ oceanografia.ufes.br/files/field/anexo/aspectos_reprodutivos_do_robalo.pdf

Sales, G. Gestão de Unidades de Conservação federais no Brasil: burocracia e poder simbólico. Florianópolis, Dissertação (Mestrado em Administração) - UFSC, 2012. Disponível em: http://repositorio.ufsc.br/xmlui/handle/123456789/94158

São Paulo (Estado). Secretaria do Meio ambiente. Fundação para a Conservação e a Produção Florestal. Manual de Gestão das Unidades de Conservação do Estado de São Paulo. São Paulo: Páginas \& Letras Editora e Gráfica, 2014.

Silva, L. F.; De Souza, T. R. D. S.; Molitzas, R.; Barrella, W.; Ramires, M. Aspectos socioeconômicos e etnoecológicos da Pesca Esportiva praticada na Vila Barra do Una, Peruíbe/SP. Unisanta Bioscience, 5(1), 130-142, 2016. Disponível em: https://periodicos.unisanta.br/index.php/ bio/article/view/646

Silvano, R. A. M.; Begossi, A. Ethnoichthyology and fish conservation in the Piracicaba River (Brazil). Journal of ethnobiology, 22(2), 285-306, 2002.

Silvano, R. A. M.; Maccord, P. F.; Lima, R. V.; Begossi, A. When does this fish spawn? Fishermen's local knowledge of migration and reproduction of Brazilian coastal fishes. Environmental Biology of Fishes, 76(2), 371-386, 2006. Disponível em: https://link.springer.com/article/10.1007/ s10641-006-9043-2

Silvano, R.A.M.; Salivonchyk, S.V.; Begossi, A. A segurança alimentar de comunidades pesqueiras do Sudeste do Brasil: dimensões complementares e um exemplo com o robalo. Segurança Alimentar e Nutricional, 21(1), 404-416, 2014. doi: 10.20396/san.v21i1.1667
SMA - Secretaria do Meio Ambiente do Estado de São Paulo. Estudo técnico para Recategorização de Unidade de Conservação e Criação do Mosaico de UCs JuréiaItatins, 2013. Disponível em: <http://www.jureia.com.br/ jureiaitatins.pdf $>$. Acesso em: jun. 2020.

SNUC - Sistema Nacional de Unidades de Conservação. Lei No 9.985, de 18 de julho de 2000. Regulamenta o art. 225, § 1o, incisos I, II, III e VII da Constituição Federal, institui o Sistema Nacional de Unidades de Conservação da Natureza e dá outras providências. Brasília: DOU de 19/07/2000. Disponível em: http://www.planalto.gov.br/ccivil_03/leis/ 19985.htm\#: :text=LEI\%20No\%209.985\%2C\%20DE\%20 $18 \% 20 \mathrm{DE} \% 20 \mathrm{JULHO} \% 20 \mathrm{DE} \% 202000$.etext=Regulamenta $\% 20$ o $\% 20$ art.,Natureza $\% 20 \mathrm{e} \% 20 \mathrm{~d} \% \mathrm{C} 3 \% \mathrm{~A} 1 \% 20$ outras $\% 20$ provid $\%$ C3\%AAncias.

Souza, T. R. D. S.; Oliveira, L. P.; Cardoso, G. S.; Rocha Barreto, T. M. R.; Gaulia, L. A.; Barrella, W.; Ramires, M. Composição e abundância da ictiofauna capturada pela pesca esportiva embarcada na Reserva de Desenvolvimento Sustentável Barra do Una, Peruíbe-SP. In: Anais do Encontro Nacional de Pós Graduação, Santos, 2(1), 34-41, 2018.

Souza, M.R.; Barrella, W. Etnoictiologia dos Pescadores Artesanais da Estação Ecológica de Juréia Itatins (São Paulo-Brasil). In: Diegues, A.C. (Org.). Enciclopédia Caiçara. Vol. 1. O Olhar do Pesquisador. São Paulo: Editora HUCITEC-NUPAUB-CEC/USP, 2004.

Taylor, R. G.; Whittington, J. A.; Grier, H. J.; Crabtree, R. E. Age, growth, maturation, and protandric sex reversal in common snook, Centropomus undecimalis, from the east and west coasts of South Florida. Fisheries Bulletin, 98, 612-624, 2000. Disponível em: https://spo.nmfs.noaa.gov/ content/age-growth-maturation-and-protandric-sex-reversal-common-snook-centropomus-undecimalis-east

Teixeira, L.D. Análise reprodutiva de Centropomus parallelus Poey, 1860 capturados pela atividade pesqueira na Reserva de Desenvolvimento Sustentável Barra do Una (Peruíbe/SP). Santos, Dissertação (Mestrado em Ecologia) - Unisanta, 2020.

Teramoto, C. S.; Diegues, A. C. S. A. Conflicts between artisanal and recreational fisheries from Bertioga/SP and proximity. In: Program book of the 7th World Recreational Fishing Conference on Change, transformation and adap- 
tation in recreational fishing. Campinas, 4 de set., 2014.

Tonini, W. C. T.; Braga, L. G. T.; Nova, D. L. D. V. Dieta de juvenis do robalo Centropomus parallelus Poey, 1860 no sul da Bahia, Brasil. Boletim do Instituto de Pesca, 33(1), 85-91, 2007.

Tsuruda, J. M.; Nascimento, R. B.; Barrella, W.; Ramires, M.; Rotundo, M. M.; A pesca esportiva e o perfil socioeconômico na Ponta dos Galhetas, Praia das Astúrias, Guarujá/SP. Unisanta Bioscience, 2(1), 22-34, 2013. Disponível em: https://periodicos.unisanta.br/index.php/bio/article/view/126
Winner, B. L.; Blewett, D. A.; Mcmichael JR, R. H.; Guenther, C. B. Relative abundance and distribution of Common Snook along shoreline habitats of Florida estuaries. Transactions of the American Fisheries Society, 139(1), 62-79, 2010. doi: 10.1577/T08-215.1 